\title{
CONF-950682--6
}

\section{Analysis of Weld Solidification Cracking in Cast Nickel Aluminide Alloys'}

\author{
M. L. Santella and Z. Feng \\ Metals and Ceramics Division \\ Oak Ridge National Laboratory \\ Oak Ridge, TN
}

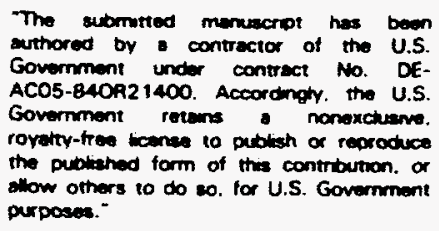

DISCLAIMER

\begin{abstract}
This report was prepared as an account of work sponsored by an agency of the United States Government. Neither the United States Government nor any agency thereof, nor any of their employees, makes any warranty, express or implied, or assumes any legal liability or responsibility for the accuracy, completeness, or usefulness of any information, apparatus, product, or process disclosed, or represents that its use would not infringe privately owned rights. Reference herein to any specific commercial product, process, or service by trade name, trademark, manufacturer, or otherwise does not necessarily constitute or imply its endorsement, recommendation, or favoring by the United States Government or any agency thereof. The views and opinions of authors expressed herein do not necessarily state or reflect those of the United States Government or any agency thereof.
\end{abstract}

'Research sponsored by the U.S. Department of Energy, Assistant Secretary for Energy Efficiency and Renewable Energy, Office of Industrial Technologies, Advanced Industrial Materials Program, and the Division of Materials Science, under contract DE-ACO5840R21400 with Martin Marietta Energy Systems, inc. 


\section{DISCLAIMER}

Portions of this document may be illegible in electronic image products. Images are produced from the best available original document. 


\begin{abstract}
A study of the response of several nickel aluminide alloys to SigmaJig testing was done to examine their weld solidification cracking behavior and the effect of $\mathrm{Zr}$ concentration. The alloys were based on the Ni-8Al$7.7 \mathrm{Cr}-1.5 \mathrm{Mo}-0.003 \mathrm{~B} \mathrm{wt} \%$ composition and contained $\mathrm{Zr}$ concentrations of $3,4.5$, and $6 w t \%$. Vacuum induction melted ingots with a diameter of 2.7 in and weight about $18 \mathrm{lb}$ were made of each alloy, and were used to make $2 \times 2 \times 0.030$ in specimens for the Sigmaijig test. The gas tungsten arc welds were made at travel speeds of 10,20, and $30 \mathrm{ipm}$ with heat inputs of 2-2.5 kJ/in. When an arc was established before traveling onto the test specimen centerline cracking was always observed. This problem was overcome by initiating the arc directly on the specimens. Using this approach, the $3 \mathrm{wt} \% \mathrm{Zr}$ alloy withstood an applied stress of $24 \mathrm{ksi}$ without cracking at a welding speed of $10 \mathrm{ipm}$. This alloy cracked at $4 \mathrm{ksi}$ applied at $20 \mathrm{ipm}$, and with no applied load at $30 \mathrm{ipm}$. Onty limited testing was done on the remaining alloys, but the results indicate that resistance to solidification cracking increases with $\mathrm{Zr}$ concentration. Zirconium has limited solid solubility and segregates strongly to interdendritic regions during solidification where it forms a $\mathrm{Ni}$ solid solution- $\mathrm{Ni}_{\mathrm{z}} \mathrm{Zr}$ eutectic. The volume fraction of the eutectic increases with $\mathrm{Zr}$ concentration. The solidification cracking behavior of these alloys is consistent with phenomenological theory, and is discussed in this context. The results from SigmaJig testing are analyzed using finite element modeling of the development of mechanical strains during solidification of welds. Experimental data from the test substantially agree with recent analysis results.
\end{abstract}

PREVIOUS WORK $(1,2)$ ON WELDING CAST Ni $\mathrm{NI}_{3}$ alloys showed they were susceptible to solidification cracking in weld fusion zones. It was also shown that a $\mathrm{Ni}-\mathrm{Zr}$ eutectic was associated with solidification cracks, and that the occurrence of cracking depended on the $\mathrm{Zr}$ concentration of the alloys. Because it could have important implications for welding filler metal development, a more detailed examination of the effect of $\mathrm{Zr}$ on the solidification cracking behavior of cast $\mathrm{Ni}_{3} \mathrm{Al}$ alloys was the subject of this study. The Sigmajig test developed by Goodwin $(3,4)$ was used to determine the effect of $\mathrm{Zr}$ concentration, welding parameters and specimen preloading on solidification cracking. The susceptibility of the $\mathrm{Ni}_{3} \mathrm{Al}$ to cracking is relatively high, and it necessitated modification of the usual Sigmajig test approach $(3,4)$. A numerical analysis of the test conditions was used to explain the various experimental observations.

\section{Materials and Experimental Procedures}

Three ingots were prepared from pure charge materials by vacuum arc meiting and casting into 2.7 -in-diameter $x 6$ in copper molds. The alloys were based on the $\mathrm{Ni}$ 8Al-7.7Cr-1.5Mo-0.003B wt\% system. Their designations and nominal $\mathrm{Zr}$ concentrations are: $14993-3 \mathrm{wt} \% \mathrm{Zr}$; 14994 - 4.5 wt\% Zr; and, $14995-6$ wt\% Zr. Chemical analysis for the ingots are not presently available, but experience showed that recovery of alloy elements for this melting and casting procedure was excellent.

For Sigmaijg testing, 0.030 -in-thick discs were cut from the castings and trimmed to produce specimens that were $2 \times 2$ in. The corners of these squares were slightly cropped because a true $2 \times 2$ in square requires a 2.8 in circular section size. The ingots were stress relieved for $1 \mathrm{~h}$ at $950^{\circ} \mathrm{C}$ before machining. Sigmajig testing involves making an autogenous gas tungsten arc weld on a sheet specimen that is loaded to a known transverse stress level prior to weiding. The apparatus 
and general procedure for the Sigmajig testing are described elsewhere $(3,4)$.

The welded specimens were inspected visually and optically at low magnification (up to $30 \mathrm{X}$ ) for evidence of cracking. Selected specimens were also examined metallographically, and subjected to image analysis and microchemical analysis in an electron microprobe (EPMA). Microchemical analysis was done using standards and wavelength dispersive spectrometers.

Computational Analysis. The computational analysis used the properties of the $3 w t \% \mathrm{Zr}$ alloy, and essentially followed the approach described in (5). The analysis was based on thermomechanically uncoupled finite element formulation. The temperature history of the specimen was first calculated independently of the stress analysis, and then used as the thermal loading in the stress calculation. In light of the thickness of the specimen, the heat transfer in the specimen was treated as a two-dimensional heat conduction problem and the geometrically nonlinear plane stress condition was assumed in the mechanical model. Due to symmetry with respect to the weld centerline, only half of the specimen needed to be modeled in this study. It was further assumed that the specimen did not crack in the analysis.

In the heat transfer analysis, the heat flux from the moving welding arc was assumed to have a spatial distribution of radial symmetric Gaussian distribution in the plane of the specimen, but uniform in the thickness direction. The arc beam radius in the Gaussian distribution was taken to be 0.062 in, same as the electrode diameter. A constant arc efficiency of $70 \%$ was used for GTAW. The convective and radiative heat losses from the surfaces of the specimen were considered in the model and treated as part of the internal heat generation/loss term (body flux) in the heat diffusion equation because of the 2-D assumption.

Temperature dependent thermophysical properties were used in the heat transfer model. In particular, the release of the latent heat of fusion in the solidification temperature range $\left(1640-1433 \mathrm{~K}, 1367-1160^{\circ} \mathrm{C}\right)$ was assumed to follow the relation as obtained from the differential thermal analysis in which the release rate is highest in the early stage of solidification. About $80 \%$ of the total latent heat $(195.6 \mathrm{~J} / \mathrm{g})$ was released before temperature dropped to $1300^{\circ} \mathrm{C}$ in the analysis. This treatment of latent heat was consistent with some recent studies (6) in which the release of latent heat was based on the consideration of microscopic solidification kinetics.

Using the model discussed above, the calculated fusion zone widths were compared very well with the actual weld bead widths for all three welding conditions.

The mechanical model consisted of the specimen and the steel grips of the loading train, shown schematically in Figure 1. They were discretized with eight-node second order isoparametric quadrilateral elements with a reduced integration scheme. No relative displacement between the

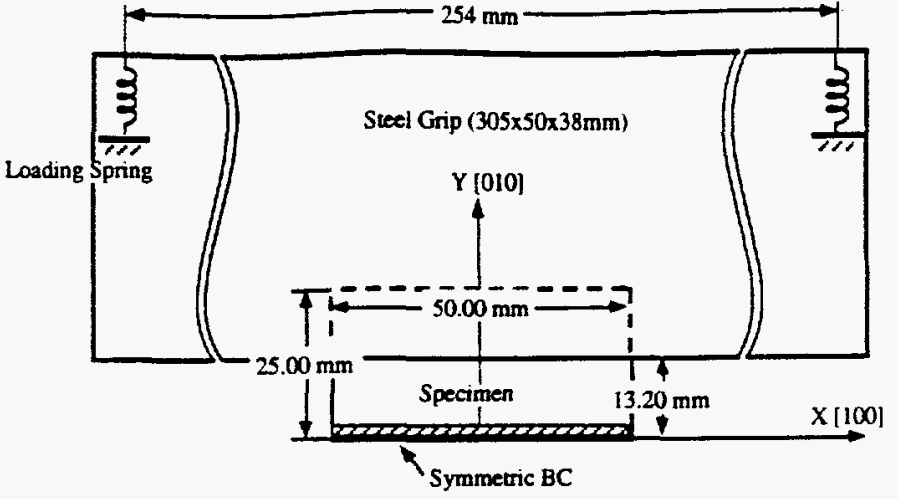

Figure 1. Schematic representation of the Sigmaijg test showing boundary conditions for the stress analysis.

steel grips and the specimen was allowed in the model. The loading mechanism of the Sigmajig test was modeled with a pair of "push" springs (5), with a load and displacement relation of

$$
F=1621.4 u_{y}-135.73 \sigma_{0}
$$

where $F(N)$ is the force in the spring, $u_{y}(\mathrm{~mm})$ the displacement of the spring in the direction normal to the weld centerline, relative to its position after pre-loading. $\sigma_{\circ}(\mathrm{ksi})$ is the prescribed stress level for a given test.

In the tests where no pre-stress was applied, the "push" springs were eliminated in the model. However, the steel grips were retained.

The material constitutive behaviors were assumed as temperature dependent but time (rate) independent elasto-plastic ones. The elastic strain rate and plastic strain rate were additive and the plastic deformation was governed by the Mises yield surface and the associated flow rule. The stress-strain curves up to $1050^{\circ} \mathrm{C}$ were experimentally determined using the uniaxial tensile test and extrapolated for temperatures between $1050^{\circ} \mathrm{C}$ and the liquidus temperature $\left(1367^{\circ} \mathrm{C}\right)$.

Since the mechanical responses of the Sigmajig specimen were analyzed based on the formulation of continuum mechanics solfids, the effects of weld pool solralficatiomreededspecial considerations. In this study, the solidification effects were included for the elements representing the resolidified weld metal by modifying the constitutive relations in the solidification temperature range. Detailed descriptions were given in $(5,6)$.

\section{Results and Discussion}

Microstructure. A microstructure from a specimen of the 14993 casting with $3 w t \% \mathrm{Zr}$ is shown in Fig. 2, and it typifies the microstructures found in all $Z r$-containing castings of this base composition in that it consists of a two-phased matrix and an interdendritic phase. The matrix in these alloys consists of about $90-95$ vol\% of the 


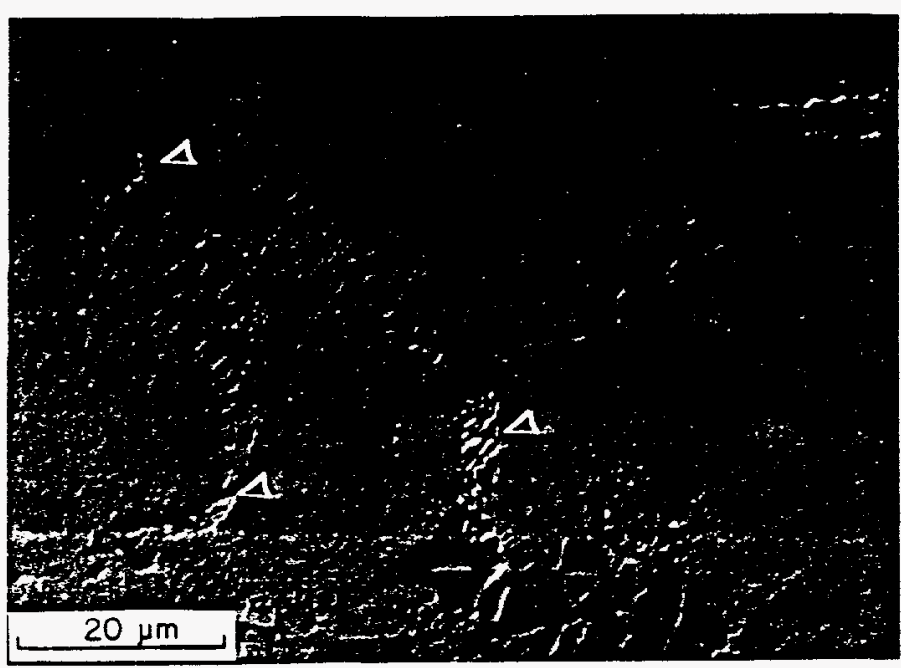

Figure 2. Microstructure of 3 wt\% Zr casting.

ordered $\mathrm{LI}_{2}$ phase $\mathrm{Ni}_{3} \mathrm{Al}\left(\gamma^{\circ}\right)$ which contains a network of the disordered $\gamma$ phase. Depending on the composition and the cooling conditions, these cast alloys can also contain up to about 19 vol\% of the eutectic, $\mathrm{Ni}_{-} \mathrm{Ni}_{5} \mathrm{Zr}$, which is indicated by arrows in Fig. 2.

Weld fusion zones can contain even higher amounts of the eutectic as shown in Fig. 3, which gives the results of volume fraction measurements taken on GTA welds made at $10 \mathrm{ipm}$. Figure 3 shows that the volume fraction of eutectic increased linearly with $\mathrm{Zr}$ concentration up to a maximum of $28 \mathrm{vol} \%$ at a nominal $\mathrm{Zr}$ concentration of $6 w t \%$. The general effect $\mathrm{Zr}$ had on weld fusion zone microstructure is illustrated in Fig. 4 which compares the GTA weld microstructures from the $3 w t \% \mathrm{Zr}$ and $6 \mathrm{wt} \%$ $\mathrm{Zr}$ alloys. The higher amount of eutectic in the weld fusion zones is attributed to the higher cooling rate of welds compared to castings ( 7 ).

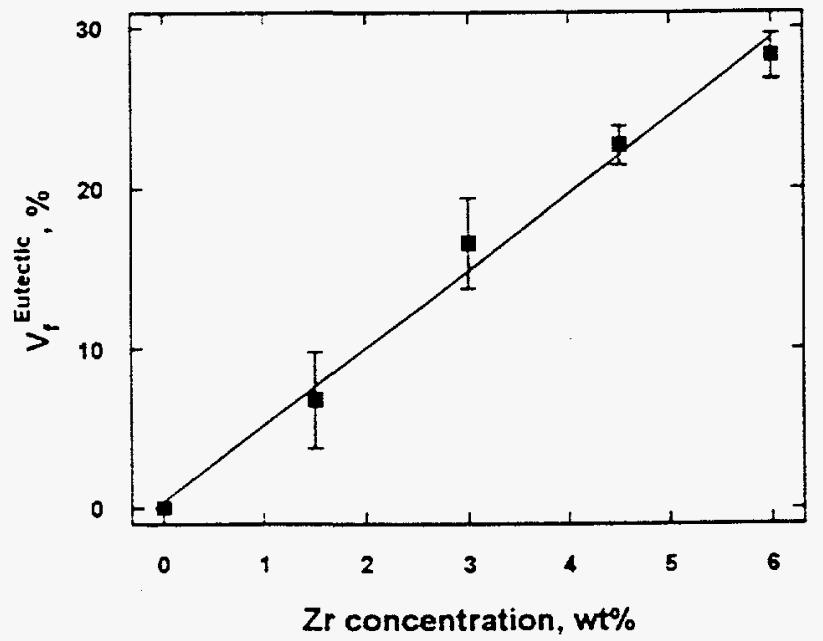

Figure 3. Variation of $\mathrm{Ni}_{-} \mathrm{Ni}_{5} \mathrm{Zr}$ eutectic in weld fusion zones with $\mathrm{Zr}$ concentration.

Sigmajig test procedure. Based on extensive studies
$(3,4)$ of the variation of Sigmajig test results with welding parameters, Goodwin established a 'standard' condition for testing 0.010-in-thick stainless steel consisting of a 0.035 in arc lengtr, 20 . $2.35 \mathrm{ipm}$ welding speed, and argon shielding. In tnis procedure, the arc is established before traveling onto the specimens.
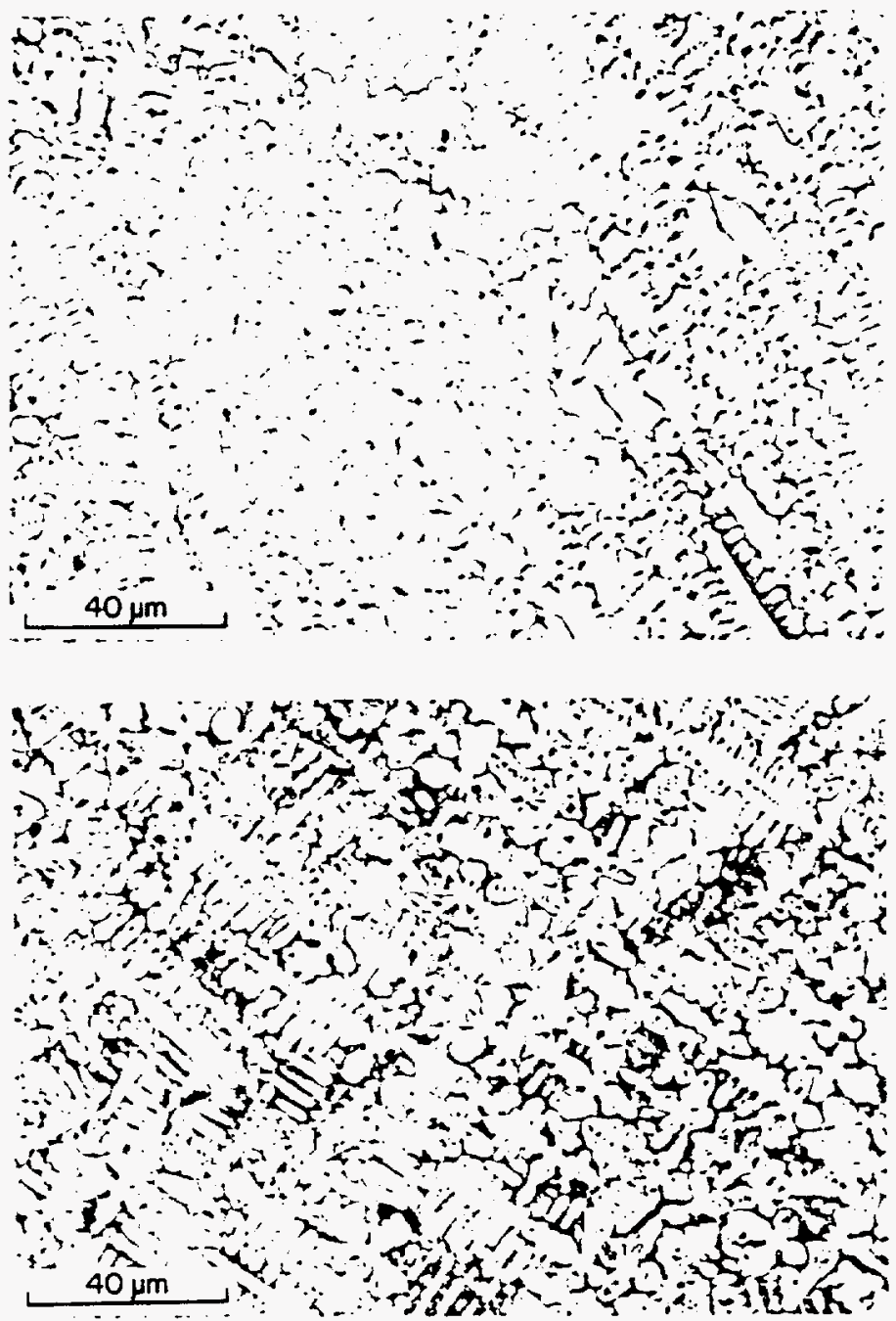

Figure 4. Microstructures in weld fusion zones of $3 w t \%$ $\mathrm{Zr}$ alloy (top), and $6 \mathrm{wt} \% \mathrm{Zr}$ alloy (bottom).

Initial tests on the cast $\mathrm{Ni}_{3} \mathrm{Al}$ were run using the same arc length and speed, but with the current adjusted to produce full penetration welds on our 0.030 -in-thick specimens. Under these conditions each weld cracked along its centerline for the entire length, and no useful data were obtained. Because of the apparent potential of the Sigmajig test for quantifying compositional effects on solidification cracking, it was decided to make minor modifications to the recommended testing procedure. The first change made was to reduce the welding speeds. This decision was based on previous studies of $\mathrm{Ni}_{3} \mathrm{Al}$ alloys which showed that their sensitivity to both solidification and heat affected zone cracking decreased 
with welding speed $(8,9)$. The second change made was to initiate the arc on the specimen. This decision was based on the observations made during the process of establishing welding parameters for the $\mathrm{Ni}_{3} \mathrm{Al}$ alloy specimens that initiating the arc on specimens often resulted in welds which did not crack. The motivation for these modifications was to produce enough sensitivity to permit testing of the relatively crack susceptible cast $\mathrm{Ni}_{3} \mathrm{Al}$ alloys.

Sigmaing test results. Our modified test procedure consisted of initiating the GTA arc on the test specimens at a distance of $3 \mathrm{~mm}$ from their edge. The tests were then conducted using three sets of welding parameters: (1) 30 A @ 10 ipm; (2) 50 A @ 20 ipm; and, (3) 75 A@ $30 \mathrm{ipm}$. In each case the arc length was set to 0.035 in, and argon shielding was used. These parameters each produce welds that were full penetration with bead widths of $3-3.5 \mathrm{~mm}$ on both surfaces of the specimens. Our intention was to maintain a constant heat input of 2.08 $\mathrm{kJ} / \mathrm{in}$, but, a heat input of $2.5 \mathrm{~kJ} / \mathrm{in}$ was required to produce the desired bead shape at the lowest welding speed. Presumably, this was due to increased time for heat conduction into the base metal at the lowest speed.

The results of the Sigmajig tests are summarized in Table 1. Most of the testing was done with the $3 \mathrm{wt} \% \mathrm{Zr}$ alloy because only a limited number of specimens were available for the remaining alloys. For the $3 \mathrm{wt} \% \mathrm{Zr}$ alloy, the threshold stress at $10 \mathrm{ipm}$ exceeded $24 \mathrm{ksi}$. The actual threshold stress could not be determined because specimens could not be reliably gripped in the Sigmajig apparatus at the level of applied load required to impose higher stresses. At the welding speed of $20 \mathrm{ipm}$ the threshold stress was $4 \mathrm{ksi}$. At the $30 \mathrm{ipm}$ welding speed, specimens centerline cracked in the Sigmajig grips even with no applied load.

Table 1. Threshold stresses for solidification cracking determined from Sigmajig testing of cast $\mathrm{Ni}_{3} \mathrm{Al}$ alloys.

\begin{tabular}{|c||c|c|c|}
\hline \multirow{2}{*}{$\begin{array}{c}\text { Speed, } \\
\text { ipm }\end{array}$} & \multicolumn{3}{|c|}{ Zr concentration,wt\% } \\
\cline { 2 - 4 } & 3 & 4.5 & 6 \\
\hline 10 & $>24 \mathrm{ksi}$ & - & - \\
\hline 20 & $4 \mathrm{ksi}$ & $6 \mathrm{ksi}$ & $8 \mathrm{ksi}$ \\
\hline 30 & 0 & - & $>0$ \\
\hline
\end{tabular}

Testing of the remaining two alloys concentrated on the $20 \mathrm{ipm}$ because of the likelihood of inducing the desired response. At the $20 \mathrm{ipm}$ welding speed, the threshold stresses of the $4.5 \mathrm{wt} \% \mathrm{Zr}$ and $6 \mathrm{wt} \% \mathrm{Zr}$ alloys were $6 \mathrm{ksi}$ and $8 \mathrm{ksi}$, respectively. Only the $6 \mathrm{wt} \% \mathrm{Zr}$ alloy was tested at $30 \mathrm{ipm}$, and it did not crack under the conditions of no applied load.
These results demonstrate that initiating the arc on the specimen enables the Sigmajig test to discriminate the cracking susceptibility of these three alloys. The threshold stress data for the 3 wt\% $\mathrm{Zr}$ alloy show that, at approximately the same heat input, increasing the welding speed used for the Sigmajig test increases the cracking susceptibility of the $\mathrm{Ni}_{3} \mathrm{Al}$ alloys. The observations about the effect of heat input on threshold stress are consistent with (4). The threshold stress data at the $20 \mathrm{ipm}$ welding speed show that the tendency to crack decreases as the $\mathrm{Zr}$ concentration increases. Though limited, the observations made at the $30 \mathrm{ipm}$ welding speed support this conclusion.

The observations about the effect of $\mathrm{Zr}$ on threshold stress are consistent with the phenomenological theory of weld solidification cracking developed by Borland (10). This well-known theory, based on solidification of idealized binary eutectic alloys, attributes weld cracking to the inability of certain microstructures to 'heal' during solidification. In this case, the term 'healing' refers to the process of liquid being able to flow into cracks that may initiate during the solidification process. Borland further proposed that in a binary eutectic system, the susceptibility to hot cracking would increase rapidly with solute content up to the solid solubility limit, then rapidly decrease to a solute content between the solid solubility limit and the eutectic composition, and thereafter remain very low up to the eutectic point. Although it is not specifically discussed, this theory implies that cracking susceptibility depends on the liquid volume fraction present at the time solidification is completed.

Solidification in the cast $\mathrm{Ni}_{3} \mathrm{Al}$ alloys is more complicated than in simple binary systems (11), but our data on these particular alloys suggest their solidification cracking behavior agrees substantially with the concepts proposed by Borland. The $\mathrm{Zr}$ solubility in the $\mathrm{Ni}_{3} \mathrm{Al}$ alloys is limited, and microchemical analyses confirmed that $\mathrm{Zr}$ partitioned preferentially to the interdendritic regions where it formed a Ni-Ni $\mathrm{Z}_{5} \mathrm{r}$-type eutectic constituent in the microstructures. The image analysis data shown in Fig. 3 confirmed that the volume fraction of eutectic, and, therefore, the amount of liquid present when solidification was completed, increased with $\mathrm{Zr}$ concentration. The Sigmajig data from the $20 \mathrm{ipm}$ welds show that the threshold stress for cracking increases over this same $\mathrm{Zr}$ concentration range. The threshold stress for cracking must be inversely related to solidification cracking susceptibility, i.e. the higher the threshold stress the higher the resistance to cracking. Because of its limited solid solubility, the increase in $\mathrm{Zr}$ concentration is not expected to influence the mechanical properties of the $\mathrm{Ni}_{3} \mathrm{Al}$ matrix phase. Therefore, it is concluded that the primary reason threshold stress increases with $\mathrm{Zr}$ concentration for the cast $\mathrm{Ni}_{3} \mathrm{iAl}$ alloy is because the volume fraction of eutectic liquid present at the time of complete solidification is also increased. 
Computational analysis resutts. Explanation of the effects of arc initiation site and welding speed on cracking response are based on computational analysis of the Sigmajig test procedure. The analysis indicated that the highest transverse mechanical strains in the Sigmajig test were experienced near the site of the weld start location, and this prediction was consistent with our observations about crack initiation sites on the test specimens. The transverse strain histories at the site of maximum strain for three different conditions at $10 \mathrm{ipm}$ are presented in Fig. 5 for the $3 \mathrm{wt} \% \mathrm{Zr}$ alloy. These data show that relatively high positive strains were predicted for the situation where the arc was established before it passed onto the specimen (indicated as $0 \mathrm{~mm}$ ) even when there was no applied load other than the restraint due to fixturing. Because the predicted strains are positive above the liquidus temperature, $1160^{\circ} \mathrm{C}$, centerline cracking is expected. In contrast, the transverse strains that developed when welding was initiated on the specimen, $3 \mathrm{~mm}$ from its edge, were primarily negative, but increased with applied load. Centerline cracking would not be expected for these two conditions. The predictions associated with Fig. 5 agree with our experimental observations.

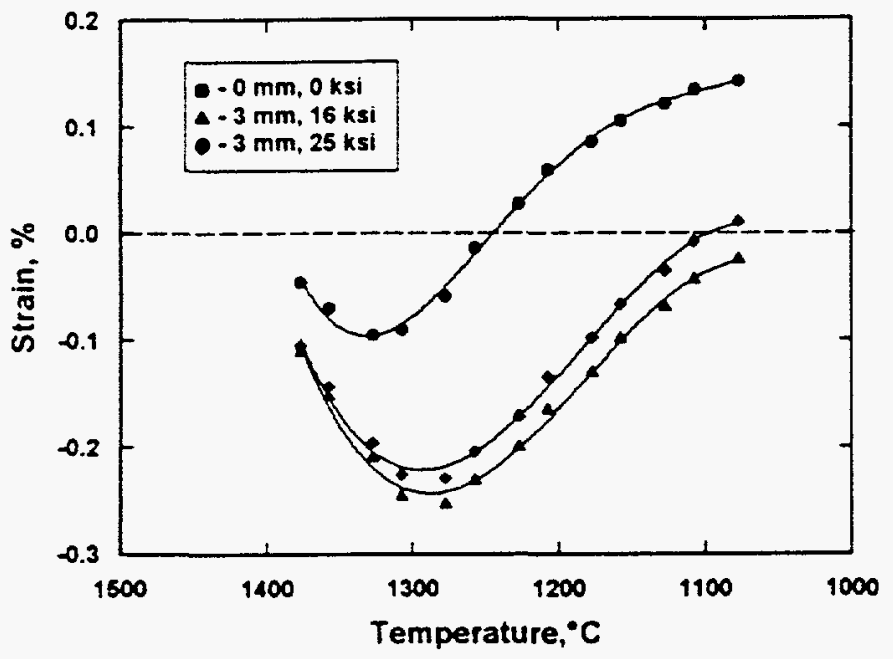

Figure 5. Effect of weld initiation site on transverse strain.

The effect welding speed has on transverse strains in the $3 w \% \mathrm{Zr}$ alloy is illustrated in Fig. 6 for three welds where each was initiated on the specimen. These data confirm that the susceptibility for centerline cracking increases with welding speed. Based on these data, only the weld made at $10 \mathrm{ipm}$ experiences negative transverse strains to temperatures below the liquidus, and this specimen is predicted to survive testing without cracking. These observations also agree with the experiments.

The situation for testing at $20 \mathrm{ipm}$ was of particular interest because it was at this welding speed that a clear threshold stress was measured for all three alloys.

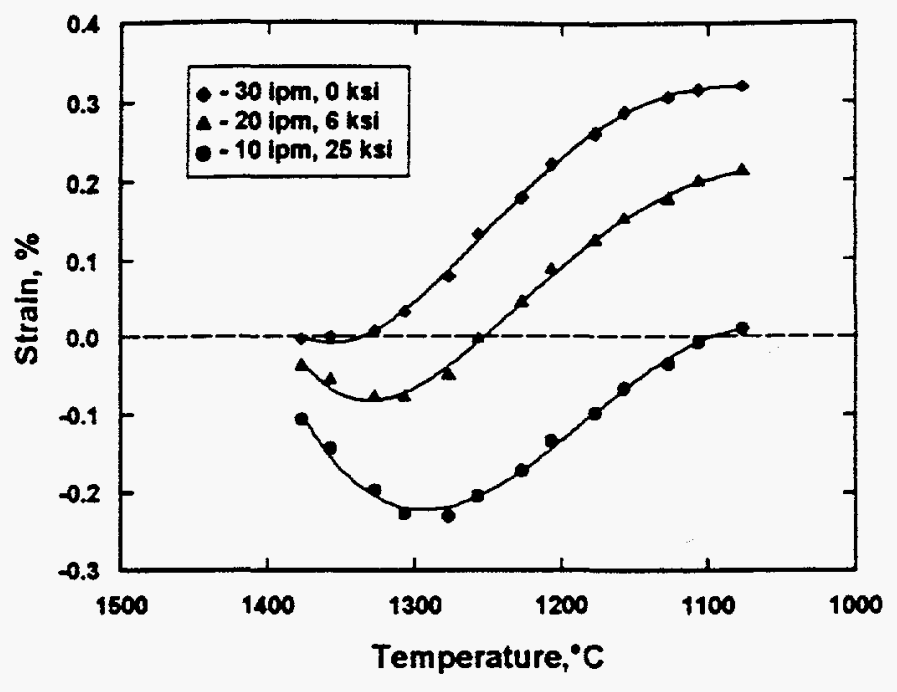

Figure 6. Effect of welding speed on transverse strains.

Transverse strain histories for welds made below (2 ksi) and above $(6 \mathrm{ksi})$ the threshold stress for the $3 \mathrm{wt} \% \mathrm{Zr}$ alloy are shown in Fig. 7. These data show that transverse strains become more positive as the applied stress increases, but that the differences in strain histories for these two specimens is slight. The model is not able to discriminate well enough between these two conditions to accurately predict the threshold stress value. Similar insensitivity to applied stress is apparent in Fig. 5.

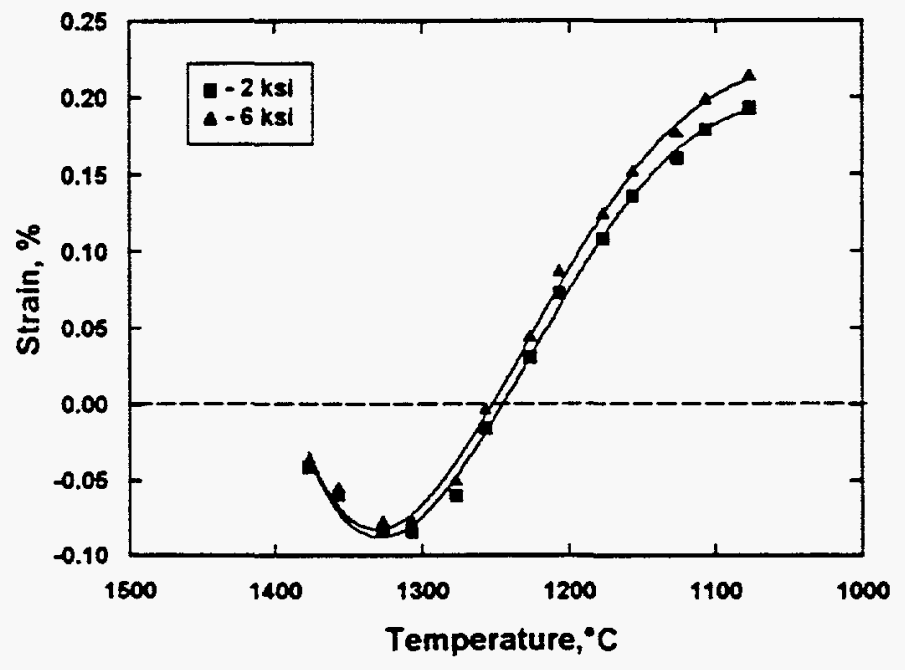

Figure 7. Effect of applied stress on transverse strain.

The computational analysis represents very well the general trends in the experimental observations made from Sigmajig testing of the cast $\mathrm{Ni}_{3} \mathrm{Al}$ alloys. It shows that welding parameters and arc initiation site play major roles in inducing centerline cracking. The analysis is not very accurate at predicting threshold stresses values. A 
possible explanation for this is that relying solely on the transverse strain as a failure criterion oversimplifies the conditions for crack initiation.

\section{Conclusions}

The data and analysis from Sigmajig testing of Ni-8Al$7.7 \mathrm{Cr}-1.5 \mathrm{Mo}-0.003 \mathrm{~B}$ wt\% alloys containing either $3,4.5$, or $6 \mathrm{wt} \% \mathrm{Zr}$ show the following:

1. Sigmaijig testing of the alloys produced sensible results only after the testing procedure was modified to initiate the welding arc on the specimen.

2. These alloys contain a $\mathrm{Ni}_{-} \mathrm{Ni}_{5} \mathrm{Zr}$ eutectic that is distributed interdendritically in weld fusion zone microstructures.

3. Both the volume fraction of the $\mathrm{Ni}-\mathrm{Ni} \mathrm{Zr}_{5}$ eutectic and the Sigmajig threshold stress increased as the $\mathrm{Zr}$ concentration increases. This general behavior is consistent with the classical theory of weld solidification cracking.

4. Computational analysis of the testing procedure and materials indicated that arc initiation on the Sigmajig specimen and reduced welding speeds resulted in a reduction of transverse mechanical strain.

5. Very good agreement was achieved between the predictions of the computational analysis and the experimental observations.

\section{Acknowledgement}

Discussion and review of the manuscript by G. M. Goodwin and J. F. King were appreciated. This work was sponsored by the U.S. Department of Energy, Assistant Secretary for Energy Efficiency and Renewable Energy, Ottice of Industrial Technologies, Advanced Industrial Materials Program, and the Divison of Materials Science, under contract DE-AC05-84OR21400 with Martin Marietta Energy Systems, Inc.

\section{References}

1. Santella, M.L., Scripta Metall., 28, 1305-1310 (1993).

2. Santella, M.L and Sikka, V.K. 'Advanced Joining Technologies for New Materials II," p 59, American Welding Society, Miami, FL (1994).

3. Goodwin, G.M., Weld. J., 66, 33-s-38-s (1987).

4. Goodwin, G.M., Weld. J., 67, 88-s-94-s (1988).

5. Feng, Z., Zacharia, T., David, S.A., to be published in Welding Journal.

6. Feng, Z., "A methodology for quantifying the thermal and mechanical conditions for weld metal solidification cracking.' Ph.D. Thesis, The Ohio State University, 1993. 7. David, S.A., Jemian, W.A., Liu, C.T., and Horton, J.A., Weld. J., 64, 22-s-28-s (1985).

8. Santella, M.L., Maguire, M.C., and David, S.A., Weld.
J., 68, 19-s-27-s (1989).

9. M.C. Flemings, "Solidification Processing," p 82, McGraw Hill Book Company, New York (1974).

10. Borland, J.C., British Weld. J., 7, 508-512 (1960).

11. Ho, C.T., Cheng, C.J., and Sekhar, J.A., Metall. Trans. A, 22A, 225-234 (1991). 